\title{
Plans unveiled to expand piloting of new dental contract
}

Pilots of a new dental contract will be expanded to more practices following promising results from evaluation of the existing pilots, it has been announced.

The new scheme for prevention-focused dental care appears to be popular with dentists involved and their patients, but nationally, dentists' leaders fear the model has 'potentially fatal flaws' that could do more damage to the financial sustainability of NHS practice.

The Department of Health and Social Care announced on 26 July 2018 that more NHS dental practices would be joining the scheme following successful results from a pilot that has been testing the new approach.

As many as 50 prototype practices in England will be selected to join the 73 that are currently testing the new system which incentivises dentists to offer full oral health assessments and self-care plans on top of traditional treatments.

The Department said that in the first year of piloting the new approach, dentists reported that:

- $90 \%$ of patients had reduced or maintained levels of tooth decay

- $80 \%$ of patients had reduced or maintained levels of gum disease

- $97 \%$ of patients said they were satisfied with the dental care they received.

The recently published evaluation report ${ }^{1}$ from the first year of testing recommended that a further group of dental practices should be recruited into the programme.

The Government has accepted this recommendation and the new practices are currently being selected and will join from October 2018 and January 2019.

The existing 73 practices are continuing to test the new approach with a new remuneration system added, which supports dentists carrying out preventative work.

If it can be shown to benefit patients, the NHS and dental practices, the scheme could be rolled out nationally from April 2020, following a thorough evaluation.

Health Minister Steve Brine said: 'The government has made great progress in improving the oral health of patients and tooth decay among children continues to decrease - but there is more we can do.

'Our new proposed NHS dental contract focuses on prevention and quality of care and will be thoroughly tested to ensure it is financially sustainable for the NHS, patients and dentists.'

Chief Dental Officer Sarah Hurley said: ‘The announcement of up to 50 more prototype practices is an important step in developing the NHS dental service. I welcome it and hope that further refinement and testing with the profession will lead us to a model that enables dentists and their teams to play their full part in the delivery of integrated care and further improvement of oral and general health.'

The BDA questioned the wisdom of expanding the pilots given that the first evaluation report had shown that the plans could further undermine the financial sustainability of NHS practice, with potential flaws in the proposed business model.

Dentist leaders have stressed that funds were needed to enable practices to widen access and spend more time with patients, but recent parliamentary questions ${ }^{2}$ had confirmed that
Government spend on NHS dentistry per head has fallen from $£ 41$ to $£ 36$ per person in just five years (2012-13 to 2016-17).

A quarter of the current hand-picked prototype practices had been unable to hit the access and activity targets, with the average practice reporting the need to work up to ten extra hours a month to deliver on their new contract, said the union.

The current contract, in operation since 2006, had fuelled problems with patient access and staff recruitment and retention in a growing number of areas, said the BDA, with more than half of young NHS dentists indicating they planned to leave NHS dentistry in the next five years.

BDA Chair of General Dental Practice Henrik Overgaard-Nielsen said: 'The current NHS dental system is fundamentally broken, with patients now travelling further or waiting longer for care. Yes, it's good to see wider testing of the prototypes, but when the one variable ministers won't change is funding cuts, we are unlikely to see progress.

'Key objectives for maintaining access, spending more time with patients and improving their oral health will not be delivered against the clock or on the cheap. We are already seeing practices having to donate time to make this new model work.'
1. Department of Health and Social Care. Dental contract reform: evaluation report 2016 to 2017 (22 May 2018). Available at https://www.gov.uk/government/publications/ dental-contract-reform-evaluation-report-2016-to-2017 (accessed 13 August 2018)
2. House of Commons. NHS: Dental Services: Written question - 147919 (5 June 2018). Available at https:// www.parliament.uk/business/publications/written-ques- tions-answers-statements/written-question/Com- mons/2018-05-24/147919/ (accessed 13 August 2018).

\section{Clarification given on amalgam restorations and revised fees}

Dentists have been given some clarification from the Scottish Government on reducing the use of dental amalgam.

Following changes to EU regulations on dental amalgam that were effective from 1 July 2018, the Scottish Government has now issued a memorandum ${ }^{1}$ on the phasing down of dental amalgam, including a list of the revised fees for nonamalgam restorations.

From 1 July 2018, an EU Regulation placed a legally-binding obligation to terminate the use of dental amalgam in deciduous teeth, and to restrict its use, except when necessary, for children under 15 years old, and for pregnant and breastfeeding women.

Following queries from members, BDA Scotland has received clarification from Scottish Government and Practitioner Services Division that 'resin' restorations are defined as: 'Any non-amalgam restoration which includes composites and resin-modified glass ionomer restorative materials.'
The code for pregnant and breastfeeding women has not altered and can be found in the Practitioner Services Discretionary fee guide $2017^{2}$.

1. Scottish Government Population Health Directorate Phasing Down of Dental Amalgam. Amendment No. 138 to the Statement of Dental Remuneration (SDR). June 2018. Available at http://www.sehd.scot.nhs. uk/pca/PCA2018\%28D\%2908.pdf (accessed 13 August 2018).

2. NHS National Services Scotland. Practitioner Services Discretionary fee guide 2017. Available at https:// nhsnss.org/media/2370/discretionaryfeeguideapril2017_001.pdf (accessed 13 August 2018). 